Servier, and UCB., Consultant of: BMS, Galapagos, Gilead, GSK, Janssen, Lilly, Novartis, Pfizer, Servier, and UCB., Grant/research support from: Servier, Alain Saraux Speakers bureau: AbbVie, Bristol-Myers Squibb, Lilly, Nordic, Novartis, Pfizer, Roche-Chugai, Sanofi and UCB, Consultant of: AbbVie, Bristol-Myers Squibb, Lilly, Nordic, Novartis, Pfizer, Roche-Chugai, Sanofi and UCB, Grant/ research support from: Roche-Chugai, Thierry Schaeverbeke Speakers bureau: AbbVie, BMS, Lilly, Novartis, Nordic Pharma, Pfizer, Roche, UCB, Consultant of: AbbVie, BMS, Lilly, Novartis, Nordic Pharma, Pfizer, Roche, UCB, Grant/ research support from: Pfizer, AbbVie, BMS, Roche, UCB, Astra, MSD, Rigel, AB-sciences, Jean Sibilia Speakers bureau: AbbVie, Lilly, MSD, Amgen, Pfizer, BMS, Janssen, Roche, Sandoz, Sanofi-Genzyme, SOBI, UCB, Novartis., Consultant of: AbbVie, Lilly, MSD, Amgen, Pfizer, BMS, Janssen, Roche, Sandoz, Sanofi-Genzyme, SOBI, UCB, Novartis., Grant/research support from: AbbVie, Lilly, Pfizer, Roche, Olivier VITTECOQ Speakers bureau: AbbVie, Bristol-Myers Squibb, Gilead, Lilly, Merck, Novartis, Pfizer; Roche-Chugai, Mylan and Sanofi, Consultant of: AbbVie, Bristol-Myers Squibb, Gilead, Lilly, Merck, Novartis, Pfizer; Roche-Chugai, Mylan and Sanofi, Grant/research support from: Novartis, Pfizer, Merck, and Bristol-Myers Squibb, Jean-Pierre Daures: None declared DOI: 10.1136/annrheumdis-2021-eular.1063

\section{OP0182 IN RA PATIENTS IN REMISSION, WHICH BIOMARKERS PREDICT SUCCESSFUL TAPERING OF CSDMARDS?}

H. Gull ${ }^{1}$, F. Ponchel ${ }^{1}$, P. Emery ${ }^{1}{ }^{1}$ Leeds Institute of Rheumatic and Musculoskeletal Medicine, Rheumatology, Leeds, United Kingdom

Background: Recommendations for the management of patients with RA who achieve stable clinical remission $\geq 6$ months with conventional synthetic (cs) disease-modifying anti-rheumatic drugs (DMARDs) are to taper (with the aim of potentially stopping), although there are currently no validated biomarkers permitting prediction of sustained remission.

Objectives: To assess the rate of sustained remission over 12 months In RA patients in remission, who received either (i) structured tapering of csDMARDs or (ii) continuation of current therapy, focusing on the value of imaging and immunological biomarkers as well as patient-reported outcome measures (PROs). Methods: RA patients $(n=200)$ prospectively attending a remission clinic, fulfilling DAS28(3v)CRP $<2.6$ for $\geq 6$ months on stable csDMARD therapy (mono or combination therapy \& no corticosteroids) were included. Patients were offered the choice of structured cs-DMARD tapering according to a pre-defined protocol (Table 1) or remaining on stable therapy. Clinical, ultrasound (US), immunological (T-cell subsets) and PRO data were collected at inclusion. Loss of remission was defined as increase of DAS28(3v)CRP >2.6. Mann-Whitney- $U$ and Chi-square tests were used to compare outcomes. After imputing missing data, regressions for predicting sustained remission were performed. AUROCs were used to compare models.

Results: The decision to taper treatment was associated with male gender, longer remission duration, normal CRP and lower grey scale scores $(p<0.05)$ Of those who tapered $64 \%(75 / 117)$ remained in clinical remission at 12 months, compared to $80 \%(66 / 83, p=0.018)$ of patients who remained on stable treatment. At 15 months 11/117 (10\%) had successfully stopped therapy.

In the tapering group, higher CRP, TJC and IRC were consistently associated with inability to sustain remission, as well as higher scores for several PROs $(p<0.05)$ with a trend for total PD $(P=0.066)$. Predicting sustained remission was modelled and retained RAQoL, total PD and a T-cell subset (Figure 1, 85\% accuracy, AUROC 0.872).

In the non-tapering group, higher CRP/ESR, SJC and shorter disease duration $(p<0.05)$ were associated with flare. No parameter was able to predict sustained remission.

Conclusion: In patients who chose to taper, the combination of clinical, PRO, US and T-cell parameters demonstrated added value for predicting sustained remission (85\% accuracy) compared to clinical parameters alone. Different biomarkers were associated with sustained remission on continued therapy. These data may assist with informed tapering of csDMARDs.

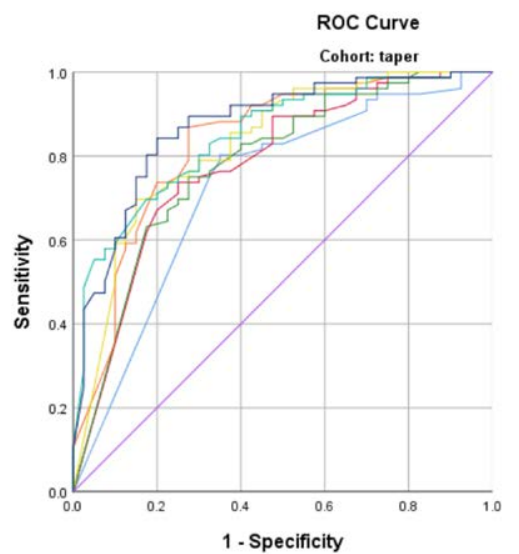

Source of the Curve Clin Only - Clin + US $-C l i n+T-C e l l s$
$C l i n+P R O+$
Clin $+P R O+U S$
Clin + PRO + T-cells - Clin + PRO + US +T-cells - Reference Line

Figure 1. AUROC Analysis of tapering cohort data

Disclosure of Interests: None declared

DOI: 10.1136/annrheumdis-2021-eular.1523

\section{\begin{tabular}{|l|l|l|l|l}
\hline OP0183 IDENTIFICATION OF A SUBGROUP OF PEOPLE &
\end{tabular} WITH RHEUMATOID ARTHRITIS CHARACTERISED BY HIGH DISABILITY OVER 10 YEARS, DESPITE LOW INFLAMMATION: RESULTS FROM TWO EUROPEAN PROSPECTIVE COHORT STUDIES}

J. Gwinnutt $^{1}$, S. Norton ${ }^{2,3}$, K. Hyrich ${ }^{1,4}$, M. Lunt ${ }^{1}$, B. Combe ${ }^{5}$, N. Rincheval ${ }^{6}$, A. Ruyssen-Witrand ${ }^{7}$, B. Fautrel ${ }^{8,9}$, J. Chipping ${ }^{10,11}$, A. Macgregor $^{10,11}$, S. Verstappen ${ }^{1,4}{ }^{1}$ The University of Manchester, Centre for Epidemiology Versus Arthritis, Manchester, United Kingdom; ${ }^{2}$ King's College London, Health Psychology section, Institute of Psychiatry, Psychology and Neuroscience, London, United Kingdom; ${ }^{3}$ King's College London, Department of Inflammation Biology, Faculty of Life Sciences and Medicine, London, United Kingdom; ${ }^{4}$ Manchester Academic Health Science Centre, NIHR Manchester Biomedical Research Centre, Manchester University NHS Foundation Trust, Manchester, United Kingdom; ${ }^{5}$ The University of Montpellier, Department of Rheumatology, CHU Montpellier, Montpellier, France; ${ }^{6}$ The University of Montpellier, Laboratory of Biostatistics and Epidemiology, Montpellier, France; ${ }^{7}$ Hôpital Purpan, Centre de Rhumatologie, Toulouse, France; ${ }^{8}$ Pitie Salpetriere Hospital, Department of Rheumatology, Assistance Publique Hôpitaux de Paris, Paris, France ${ }^{9}$ Sorbonne University, INSERM UMRS, Pierre Louis Institute of Epidemiology and Public Health, Paris, France; ${ }^{10}$ University of East Anglia, Norwich Medical School, Norwich, United Kingdom; ${ }^{11}$ Norfolk and Norwich University Hospitals NHS Trust, Rheumatology Department, Norwich, United Kingdom

Background: Long-term studies in rheumatoid arthritis (RA) have reported low inflammation yet high disability over time. It is important to determine which factors are driving this disparity, so appropriate interventions can be used to reduce this gap.

Objectives: To identify a subgroup of people with RA with low inflammation yet high disability over 10 years, and describe their characteristics.

Methods: Data came from two cohorts of inflammatory arthritis with regula assessments over 10 years: the Norfolk Arthritis Register (NOAR, inclusion: $\geq 2$ swollen joints for $\geq 4$ weeks) from the UK and the Etude et Suivi des Polyarthrites Indifférenciées Récentes study (ESPOIR, inclusion: early RA) from France. Participants provided demographic data and completed patient reported outcomes (PROs, including the Health Assessment Questionnaire [HAQ]). The 2-component Disease Activity Score (DAS28-2C) ${ }^{1}$, a measure of inflammation, was

Table 1. csDMARD tapering schedule

\begin{tabular}{|c|c|c|c|c|c|c|}
\hline Drug & Baseline Dose & Taper 1 & Taper 2 & Taper 3 & Taper 4 & Taper 5 \\
\hline Hydroxychloroquine & $200 \mathrm{mg}$ bd & $200 \mathrm{mg}$ od & Stop & - & - & - \\
\hline Hydroxychloroquine & $200 \mathrm{mg}$ od & Stop & - & - & - & - \\
\hline Sulfasalazine & $1.5 \mathrm{~g} \mathrm{bd}$ & $1 \mathrm{~g} \mathrm{bd}$ & $1.5 \mathrm{~g}$ od & $500 \mathrm{mg} \mathrm{bd}$ & $500 \mathrm{mg}$ od & Stop \\
\hline Sulfasalazine & $1 \mathrm{~g} \mathrm{bd}$ & $1.5 \mathrm{~g}$ od & $500 \mathrm{mg}$ bd & $500 \mathrm{mg}$ od & Stop & - \\
\hline Sulfasalazine & $500 \mathrm{mg} \mathrm{bd}$ & $500 \mathrm{mg}$ od & Stop & - & - & - \\
\hline Sulfasalazine & $500 \mathrm{mg}$ od & Stop & - & - & - & - \\
\hline Methotrexate & $25 \mathrm{mg} /$ week & $15 \mathrm{mg} /$ week & 7.5mg/week & No change & Stop & - \\
\hline Methotrexate & $15 \mathrm{mg} /$ week & 7.5mg/week & No change & Stop & - & - \\
\hline Methotrexate & 7.5mg/week & No change & Stop & - & - & - \\
\hline
\end{tabular}

NB: Patients were seen 3-monthly. If they remained in remission following tapering, they proceeded to the next taper unless there is a significant clinical reason not to taper at the time of assessment (as per standard care). Order of cs-DMARD tapering applies to patients on dual/triple therapy. All but 5 (112) were on methotrexate. 